\title{
The Importance of Ease of Doing Business in Digital Disruption Era
}

Various efforts to improve the ranking of ease of doing business in Indonesia throughout 2018 are still restrained by exports and imports that have consistently tended to decline since 2015. Bank's report on the ease of doing business 2018 places Indonesia in 73rd out of 190 countries.72nd position, The downgrade of ease of doing business in Indonesia is expected to have no significant impact on investment, both domestically and internationally. The condition of the global economy in 2018 tends to be sluggish and unbalanced, followed by high global financial uncertainty. The United States economy seems to grow strongly, but inflation expectation remains high so the Fed tends to choose to raise the benchmark interest rate. The economies of Europe and China are also expected to grow slowly. Also, the volume of world trade is expected to be low due to deteriorating trade relations between countries. In the era of economic disruption, which is expected to happen until 2020, business people in Indonesia are required to constantly renew, innovate, and create diversification so that they can survive in the market. The growing competition in the market faced by business people makes company leaders tend to make changes continuously where each element must be an important pillar to support the company's vision and mission, including optimizing the strategies that have been determined to obtain profit maximization.

GCG is essentially a set of rules that regulate, manage, and supervise the relationship between company managers and stakeholders in the company to increase company value and market valuation. By implementing GCG, companies will get many benefits, such as ensuring the establishment of corporate culture, the existence of information disclosure, an effective audit system, and risk control that always refers to GCG standards. Similarly, the companies need to make GCG statements based on guidelines that are officially issued by the National Governance Policy Committee along with a description of the implementation of GCG. GCG practices 
and value-added creation are expected to meet three dimensions: compliance, conformance, and performance.

By using primary data and secondary data, the researchers tried to explore how business people perceive economic disruption and how business people save and shape their reality so that they are familiar with the economic disruption. This means that the validation of the accuracy of information is done gradually, starting from the procurement of raw data to be processed for analysis to produce themes and disruption.

Trillion in 2017. In the first semester of 2018, investment activities in the manufacturing industry sector reached IDR 121.56 trillion. At present, the industrial sector that is closely associated with the use of high technology tends to be aggressive in opening up the recruitment of new workers. The same thing also happens in the mining sector and mining services, considering that there is so much labor migration because the old companies have low value and the stress levels during work tend to be high The workforce that is sought after by companies is data analysis and business intelligence, general digital or internet-based marketing, and software programming experts. The development of the digital economy turns out to stimulate the search for new workers by prioritizing information technology skills. The quality of workforce development in Indonesia seems to be not maximal, as reflected in the Labor Development Index which only reached 60. Digital trends create many job opportunities, but most are informal and have no official legal status.

So, fast-moving digital technology demands a change of expertise, considering that the skills currently possessed by workers may not be needed in the future, so new competencies are needed. The competitiveness of companies in Indonesia in facing economic disruption and industrial revolution is very dependent on the ability to take advantage of changes along with technological advancement that has been increasing exponentially to survive, develop, and provide significant added value to all stakeholders. 
One issue that often arises in companies when executing a new strategy is organizational readiness in terms of aligning the strategy that will be executed with the business processes carried out within the organization, organizational structure, human resource competencies, and culture. Thus, a self-assessment is needed so that the direction and alignment of the company's adjustment process, including employee competency, can be identified and the agile organizational structure can run the strategy with the existing process. The challenges that arise may come from external or internal factors of the company. This means that business transformation and human resource transformation are important agendas in many companies. Companies that have succeeded in carrying out business and human resource transformation are PT. If all steps in the transformation process can be realized, the company will certainly be able to answer the challenges of change and maintain the relevance of its ecosystem. Nowadays, more and more companies in Indonesia are implementing GCG not as a regulatory obligation or something burdensome, but as part of the company's tools and guidelines in getting to know the business transformation process. GCG an operational foundation so that all strategies and management systems in the companies can be carried out properly and correctly, which ultimately raises trust from stakeholders.

Companies that have implemented GCG are proven to be able to carry out all strategies and management systems properly and correctly and bring trust from stakeholders. In general, in terms of aspects of output, outcome, and impact, the companies that have implemented GCG show significant progress. In addition to being able to encourage aspects of openness, accountability, and trust, GCG has also helped empower functions in the business unit and increased the independence of the company's organs. The implementation of GCG turns out to be able to encourage companies to continue to strive to create and introduce new values in the aspects of products, operations, and services that have an impact on improving company performance, and ultimately benefit stakeholders. 
This shows that the system is expected not only to drive the pace of business, but also to increase stakeholders' trust so that investors are interested in their shares, or other words, issuers always improve the quality of GCG to become an investor's choice, and GCG is an important consideration in the investment decision-making process. The effectiveness of an organizational structure to produce superior performance is greatly influenced by the quality of leadership and the management system implemented. Similarly, employees sometimes feel that there is no bond with the company. Employee engagement is very important in companies that are currently in the vortex of global economic disruption.

Employee engagement provides access for management to be able to improve the conditions of employees' say, stay, and strive through efforts to build high commitment and accommodate aspects of employee satisfaction with the company better, which in turn can be implemented into daily operational activities. Employee engagement is expected to foster passion, motivation, and proactive encouragement for employees to provide optimal efforts in every business activity

Competitive advantage has become a necessity for every company in Indonesia in facing economic disruption when the company wants to survive in the domestic and global markets through a massive transformation at all levels and business units operated as well as continuous innovation. The leaders have to strive to be more adaptive in facing the future that is full of volatility, uncertainty, complexity, and ambiguity, including being able to bring a positive aura to all employees.

\section{REFERENCES}

Tayipnabis, A.Z., \& Wuryaningsih, L.E. (2019). Companies in Indonesia in the vortex of global economic disruption. Advances in Social Science, Education and Humanities Research, 308, 174-177. 